\title{
A System Model of Forming Economic Competence of Future Accountants On the Basis of Contextual Approach
}

\author{
Irina G. Yakovleva ${ }^{1}$, Faina V. Povchednaia ${ }^{2}$, Oksana V. Lebedeva ${ }^{2}$, Irina V. Lushchik ${ }^{3}$, Liudmila I. Chernikova ${ }^{4}$, \\ Olga R. Semikova ${ }^{5}$, Evgeny V. Dmitriev ${ }^{5} \&$ Svetlana Y. Novoselova $^{6}$ \\ 1 Institute of Technology Branch of Ulyanovsk State Agricultural Academy named after P. A. Stolypin, \\ Dimitrovgrad, Russia \\ ${ }^{2}$ Nizhny Novgorod Pedagogical University after K. Minin, Nizhny Novgorod, Russia \\ ${ }^{3}$ Moscow University Named by S.Y. Witte, Moscow, Russia \\ ${ }^{4}$ Russian State University of Tourism and Service, Cherkizovo, Moscow region, Russia \\ ${ }^{5}$ International Institute for Economics and Humanities, Moscow, Russia \\ ${ }^{6}$ Academy of Professional Development and Professional Retraining of Educators, Moscow, Russia \\ Correspondence: Irina G. Yakovleva, Institute of Technology Branch of Ulyanovsk State Agricultural Academy \\ named after P. A. Stolypin, 433511, Ulyanovsk Province, Dimitrovgrad, Kuibysheva Street, 310, Russia. E-mail: \\ irinajakovleva@mail.ru
}

Received: April 16, 2015 Accepted: April 26, 2015 Online Published: May 28, 2015

doi:10.5539/jsd.v8n3p203 URL: http://dx.doi.org/10.5539/jsd.v8n3p203

\begin{abstract}
This article aims to develop a system model to form the economic competence of future accountants. The leading approach to the development of this model is the contextual approach which allows to dynamically modulate the subject matter and social content of the future expert professional work providing conditions for transformation of the students' learning activities into a professional activity. The system model of forming economic competence of college students submitted in the article enriches the scientific knowledge with the objectives, tasks, methodological approaches, principles, factors, leading guidelines, forms, methods, technologies and the results of economic education of the future competitive specialists. The experimental results presented in this paper demonstrate the effectiveness of the this model on the basis of contextual approach. The article submissions are of theoretical and practical value for the teachers of secondary and higher vocational education.
\end{abstract}

\section{Introduction}

\subsection{Background}

Restructuring the education sector including secondary vocational education is determined by a significant transformation of the Russian socio-economic sphere and the innovative processes in the European and global educational space. The vocational education system in modern society sets an objective of training the specialists able to quickly adapt to the changing conditions of economic reality and flexibly respond to the problems requiring urgent solutions. In the current context the implementation of the Concept for the long-term socio-economic development of the Russian Federation until 2020 the educational process should provide every future specialist not only with the fundamental theoretical knowledge but also a wide range of practical professional skills as well as professionally important personal characteristics.

Among the factors that negatively affect the quality of the staffing, as various studies show, is the dissonance between the educational content and the requirements of society and the manufacturers to the identity and the level of professional competence of college graduates. To solve the mentioned problems it is necessary to develop the strategies of secondary vocational education focused on the current state of manufacturing sector where under the influence of scientific and technological progress the deep qualitative changes are being introduced into engineering, technology and organization, the scale of production is expanding, its structure is improving, the concentration is increasing, specialization is being expanded (Masalimova \& Nigmatov, 2015). All this makes the management mechanism complicated, necessitates its compliance with the economic laws requirements. The practice has shown that the higher the specialists' level of economic competence in addition to the professional one, the greater the 
economic benefits they bring to industry with their immediate work.

In the current economic conditions in the Russian labor market there is the increasing need for highly skilled workers and mid-level professionals. The secondary vocational education significantly strengthens its position in the Russian system of education. The issues of development and improving the quality of vocational education and their solution are of highest priority in society and, in particular, in the modern Russian education system. Currently, it is the mid-level professionals who are qualified to ensure the implementation of the rapidly developing technology into the production process and change the technological culture of production.

Formation of a socially open system of non-university vocational education is regarded as a process aimed at expanding the choice to meet the life journey needs and at the same time the interests of an individual. Therefore, the educational system cannot be designed only as knowledge-centered structure. It is required to shift a vocational education paradigm from a person-centered to a personality-developing one.

\subsection{Literature Review}

The problems of secondary vocational educations are devoted the studies of A. P. Belyaeva (1995), Y. V. Esenkov (2004), N. N. Nikitina (2002), A. M. Novikov (2000), V. D. Purin (2006), N. M. Snopko (2008), E. F. Shcherbakov (2005), A. R. Shaidullina et al. (2015).

The economic education of future specialists is studied in the works of V. S. Avtonomov (2005), N. A. Banko (2002), N. V. Demicheva (2009), O. O. Martynenko (2007) and others. The development of economic thought in Russia and abroad was investigated in the works of L. I. Abalkin (1987), V. S. Avtonomov (2005), M. K. Bunkina (2000), A. B. Vifliemsky (2004), A. A. Marshall (2007), A. A. Petty (2000), I. A. Schumpeter (2004) and others.

The study of educational process organization as such in the secondary vocational institutions has shown that the economic theory is often different from the future professionals' economic practice, and in the learning process the traditional forms and methods of teaching prevail significantly. A large number of scientific papers is devoted to the problem of active learning methods including the use of simulation and role modeling and educational business games in the educational process (Abramova, 1999; Andreeva, 1999; Arutjunov, 1987; Babeshko, 2001; Burgonova, 2000; Verbitsky, 1988 etc.).

The analysis of scientific and educational literature proves that one of the promising approaches that presents a theoretical foundation of rational and complex use of various forms and methods of active learning is the contextual approach. The core of the contextual approach is a theory of contextual learning that has been developed for over 30 years in the scientific and pedagogical school (Verbitsky, 1988; Borisova, 1991; Dubovitskaya, 2004; Zhukova, 2006 and others.). The intensive development of the contextual approach to the theory and practice of vocational education once again confirms the trend towards the convergence of the learning process with real life and demonstrates the necessity of providing the students with such knowledge that will be demanded in their practical work for the company. However, in the framework of contextual approach there is the unexplored area associated with the specialists' education in the secondary vocational institutions and, in particular, within the process of forming the economic competence of the Agricultural College students.

\section{Methodological Framework}

\subsection{The Contextual Approach}

The contextual approach serves the methodological grounds for developing the model system of forming economic competence of future accountants. The practical implications of the contextual approach have become the unsolved problem of providing the continuity of education and future professional activities. In traditional use the students' learning activity is significantly different from the future professional work in its subject, objectives and motives.

In the process of contextual learning through active forms and methods of teaching it is possible to model not only the content of professional activity, but also social relations in which it is performed. In contextual education the following principles proposed by A. A. Verbitsky (1988) include: psychological and pedagogical support of personal student's involvement into educational activities; consistent modeling of the holistic content, forms and conditions of professional activity in students' learning activities; the syllabus problematic character during its unfolding in the educational process; the accordance of the organizational forms of the students' educational activity to the objectives and the syllabus; the leading role of joint activity, interpersonal interaction and dialogic communication of the educational process participants; the principle of pedagogically justified combination of new and traditional educational technologies; the principle of openness; the unity of education and upbringing of the personality ; the principle of cross-cultural students' peculiarities. 


\subsection{The Interrelation between the Contextual and Other Approaches}

The contextual approach is closely linked and organically interact with other methodological approaches to vocational education. Different approaches to education are formed under different theories and concepts. Most current approaches to education ensure the implementation and specification of the person-centered education paradigm. These include the following approaches: the personal, individual, culturological, axiological, activity-based, contextual.

\subsubsection{The Personal Approach}

The personal approach shifts the focus of vocational education from mastering a specialty as mastering professional knowledge, skills and abilities to the development of personal potential of the specialist (Serikov, 2003; Petrovskiy, 1981 et al.).

\subsubsection{The Individual Approach}

The individual approach to specialists' education is similar to the personal approach, but not identical to it. The concept of "personality" marking the social nature of a man as the bearer of consciousness and self-consciousness does not reflect all the diversity, heterogeneity of the manifestation of the essence of every individual. The unique inner identity, the depth of personality lies in its individuality. Implementing the individual approach in the process of teaching, it is necessary to focus on both components and build pedagogical process not only taking into account the students' individual characteristics, but also create conditions for the development of their personality (Leontiev, 1999; Petrovskiy, 1981; Telegina, Galimova \& Masalimova, 2015).

\subsubsection{The Culturological Approach}

The culturological approach is developed within the framework of person-oriented educational paradigm and lies in the focus of the educational process on formation of the specialist's cultural identity, formation of the student as a bearer of general and professional culture providing his life worth living in the world and in profession (Bibler, 1998; Hessen 1995; Zinchenko, 1991, et al.).

\subsubsection{The Axiological Approach}

The essence of axiological approach to the future expert's education is to guide the professional education to forming a system of universal and professional values that determine his attitude to the world, his activities, himself as a person and a professional. Today, the psychology and pedagogy focus attention on forming a value-based attitude to the world as the main objective of education (Davydov, 1986; Leonov, 1982; Scheler, 1999, et al.).

\subsubsection{The Activity Approach}

The activity approach is based on the generally accepted idea that a person moulds, develops and manifests himself in action. That is why the effectiveness of the educational process depends on the students' engagement into active, meaningful learning activities. Through the activity the students acquire social and professional experience, develop psychical functions and abilities, create a system of attitudes to the world and to himself (Bozovic, 1968; Rubinstein, 2004).

\subsubsection{The Competence-Based Approach}

The competence-based approach in education is targeting the educational process at forming specific competences. The concept of "competence-based approach" has become widespread in the early 21th century following the discussions about the problems and ways of modernization of Russian education. The competence-based approach has been chosen a conceptual foundation for the Federal State Education Standards of secondary vocational education. The competence there is treated as a system of values and personal qualities, knowledge, skills and abilities to ensure the person's readiness to competently perform professional activities. Accordingly, the competency is the competence implemented in practice. The implementation of the competency-based standards requires the development of a competency-based model of training a specialist.

\section{Materials and Methods}

We have designed the system model of forming the economic competence among the future accountants on the basis of contextual approach (Table. 1), its criteria and the research technique of the efficiency of the economic competence formation among the students in the secondary vocational education institutions. 
Table 1. The system model of the forming economic competence among the future accountants on the basis of contextual approach

\section{Methodological component}

Objective: to form the economic competence of the future accountant as a comprehensive, integrative personality characteristic that determines the level of professional competence providing the professional service of the economic entities functioning. The entities include all legal forms of ownership, the scope of the state budget and non-budgetary institutional structures.

Tasks: to create conditions for transformation of educational activity into quaziprofessional and professional ones; expansion, consolidation and systematization of the economic knowledge; improving the professional skills of accountants to solve professional problems; mastering advanced technologies; forming professionally significant qualities; students' adaptation to the real working environment, strengthening ties of educational institutions with production.

Methodological approaches: personal, individual, culturological, axiological, activity-based, competence-based and contextual.

Factors attaching the conditions of the contextual approach to education in the secondary vocational education: objective ones are associated with the potentially high degree of connection to the economy, corporate circularity of the secondary vocational education, its focus on academic engrossment for young people from the most disadvantaged families; the subjective ones are associated with the teacher's and student's personalities in secondary vocational education

\begin{tabular}{|c|c|}
\hline $\begin{array}{l}\text { Methodological principles: } \\
\text { the principle of applying axiological aspects of the } \\
\text { education content standards; the principle of } \\
\text { psycho-pedagogical supply of the student's personal entry } \\
\text { into the learning activities; consistent modeling of the } \\
\text { holistic content, forms and conditions of professional } \\
\text { activity in students' learning activities ; problematic } \\
\text { character of the syllabus during its unfolding in the } \\
\text { educational process; the suitability of the organizational } \\
\text { forms of students' educational activity for the objectives } \\
\text { and syllabus; the leading role of joint activities, the } \\
\text { principle of professional positioning; interpersonal } \\
\text { interaction and dialogic communication of the educational } \\
\text { process subjects (teachers and students, students with each } \\
\text { other); pedagogically justified combination of new and } \\
\text { traditional educational technologies; the principle of } \\
\text { openness means using any pedagogical technique } \\
\text { submitted within other theories and approaches to achieve } \\
\text { specific educational goals; the unity of teaching and } \\
\text { upbringing of the personality's professional identity; the } \\
\text { principle of forming professional identity of the student and } \\
\text { others. }\end{array}$ & $\begin{array}{l}\text { The principles of play activity organization: } \\
\text { - the didactic principles (system; accessibility; } \\
\text { problematic character of the simulation model and the } \\
\text { process of its developing in play activities, visibility and } \\
\text { simplicity of presenting the simulated processes; } \\
\text { targeting at achieving the learning outcomes; drawing on } \\
\text { basic economic knowledge of the participants; the } \\
\text { involvement character of the play within the curriculum, } \\
\text { focus on economic thinking and practicing accountant } \\
\text { skills; } \\
\text { - The principles of guiding the playing process (gradual } \\
\text { entry, complete immersion, simulation of the specific } \\
\text { conditions, content and forms of professional activities; } \\
\text { the maximum approximation of the play to real } \\
\text { professional situation; } \\
\text { - the principles of participants interaction (a joint } \\
\text { venture; competitiveness); } \\
\text { - the principles of critical appraisal of educational } \\
\text { business games results, reflection over the play activity, } \\
\text { integrated assessment. }\end{array}$ \\
\hline
\end{tabular}




\section{Substantive component}

The leading substantive lines:

- the educational activities of academic type of the subject and social context of future professional activity simulating the specialists' action;

- quasiprofessional activities simulating the conditions, content and dynamics of professional work, the employment relationship (eg, business, functional-role-playing and simulation games);

- Educational and professional activities which arrange the research and practical functions, use intellectual didactic components of the adaptive educational systems in combination with traditional ones, improving the professional competencies due to the transformation of learning activities into the professional ones.

\section{The course "Corporate economics»}

Module 1: "The company in the market." The industry-specific characteristics of the enterprise in the market. The production structure of the enterprise.

Module 2: "Material and technical facilities of the enterprise." Capital assets. Current assets. The financial resources of the company.

Module 3: "The personnel and remuneration." The Personnel of the enterprise and workforce productivity. Remuneration.

Module 4: "The key technical and economic indicators of the enterprise activity." Costs of production and sales on the cost items. Pricing. Profit and profitability. Company performance.

\section{The activity component}

Technology of contextual learning (social, subject-technological, situational - psychological contexts): role-playing; "case study"; situational problem; business game.

Forms and methods: lectures (of problematic character, contextual- informative, contextual-scientific, contextual professionally oriented, visualization lecture, provocation lecture with a pre-planned scientific or professional mistakes, lecture together, lecture-dialogue, counseling lecture, "advanced lecture "etc.); seminars (discussion seminar, research seminar, press-conference seminar, roundtable seminar, " small polemical groups" seminar and others.); research work; course and diploma design; industrial placement (introductory, technological and pre-graduation practical training)

\section{Effective component}

Result: ensuring a high level of professional competence of the graduates from the economic secondary vocational institutions on the basis of contextual approach in response to the transformation of educational activity into quasi-professional one.

\begin{tabular}{ccc}
\hline \multicolumn{3}{c}{ Integral criterion of "the economic competence" } \\
\hline \multicolumn{3}{c}{ Criteria } \\
\hline Conceptual & Instrumental & Personal-professional \\
\hline & Levels & \\
\hline Informative - reproductive & Reflective-productive & Creative \\
\hline
\end{tabular}

The developed system model of the formation of economic competence among the future accountants based on the contextual approach is a holistic system of interconnected component blocks: methodological (reflecting the objectives, tasks, methodological approaches, principles and factors of the process under study), substantive (revealing the leading lines and modules of the course " Corporate economics " ); activity (forms, methods and technologies that provide social, subject-technological and situational-psychological context of the professional accountant's activity) and effective (combining substantive, instrumental and personal-professional criteria into an integral criterion the "economic competence " and the levels of its formation : informative-reproductive, reflexive-productive and creative), creates an opportunity to cover its specificity arising from the specific implementation of the contextual approach into the college educational space in a single system. 


\section{Results}

The results of the pedagogical experiment demonstrate significant differences in the results of the experimental and control groups that indicates the effectiveness of the system model of forming the economic competence among the future accountants on the basis of contextual approach and the developed system of business games for the " Corporate economics" course creating the substantive and social content of the future accountant activity.

The distribution of the respondents of control and experimental groups according to the level of the economic competence formation at the first and third stages of the pedagogical experiment is shown in Table 2.

Table 2. The comparative analysis of the respondents distribution of the control and experimental groups according to the levels of economic competence

\begin{tabular}{llcccccc}
\hline \multirow{2}{*}{ Stages } & \multirow{2}{*}{ Groups } & \multicolumn{5}{c}{ The levels of economic competence } \\
\cline { 3 - 7 } & & \multicolumn{2}{c}{ Informative-reproductive } & Reflexive -productive & \multicolumn{2}{c}{ Creative } \\
\cline { 3 - 7 } & & Pers. & $\%$ & Pers. & $\%$ & Pers. & $\%$ \\
\hline \multirow{2}{*}{ I этап } & Control & 40 & 42,1 & 52 & 54,7 & 3 & 3,2 \\
& Experimental & 42 & 42 & 54 & 54 & 4 & 4 \\
& Control & 34 & 35,8 & 49 & 51,6 & 12 & 12,6 \\
\multirow{2}{*}{ III этап } & 12 & 12 & 40 & 40 & 48 & 48 \\
& Experimental & 12 & & & & \\
\hline
\end{tabular}

Thus, at the third stage the number of respondents in the experimental group with high, creative level of economic competence development has increased in comparison to the first stage by $44 \%$ (from $48 \%$ to $4 \%$ ), with an average, reflexive-productive level has decreased by $14 \%$ (from $54 \%$ to $40 \%$ ). The number of respondents with low, informative-reproductive level has decreased by $30 \%$ (from $42 \%$ to $12 \%$ ). In the control group there are positive changes, but they are not significant. The number of respondents with a high, creative level has increased from 3.2\% to $12.6 \%$ (by $9.4 \%$ ), with an average, reflexive-productive level - has fallen from $54.7 \%$ to $51.6 \%$ (by $3.1 \%$ ). The number of respondents with low, informative-reproductive level has also decreased from $42.1 \%$ to $35.8 \%$ (by $6.3 \%)$.

The comparative analysis of the experimental results at the third stage has demonstrated that the number of respondents with a high, creative level in the experimental group (48\%) exceeds the number in the control group $(12.6 \%)$ by $35.4 \%$. The indicators of the average reflexive-productive level are lower by $11.6 \%(51.6 \%-40 \%)$, and the low, informative-reproductive level is less than $23.8 \%(35.8 \%-12 \%)$ which indicates the positive results of the performed.

\section{Conclusion}

The developed system model of the process of forming economic competence of future accountants on the basis of contextual approach which is a holistic system of interconnected component blocks (methodological, substantive, activity and effective) gives an opportunity to cover its specificity arising from the particular implementation of the contextual approach into college educational space in a single system and helps to describe and expand the knowledge of the researched process in order to its transform and manage it efficiently. The effective block of the model reflects the basic performance criteria of the process under study (substantive, instrumental and personal-professional) combined into an integral criterion "the economic competence" and the levels of its formation (informative- reproductive, reflexive-productive and creative). The findings of the pedagogical experiment show significant differences between the results in the experimental and control groups that prove the effectiveness of the system model of forming the economic competence of future accountants on the basis of contextual approach.

\section{References}

Abalkin, L. I. (1987). A new type of economic thinking. Moscow. Economics, 191.

Abalkin, L. I. (2001). Russian school of economic thought: the search for self-determination. Problems of Economics, 2.

Abramova, G. S., \& Stepanovich V. A. (1999). Business games. Luxembourg, 192.

Andreeva, E. V. (1999). Principles of duality in the business game as a form of contextual learning. Moscow, 23. 
Arutjunov, Y. S. (1987). Methodological issues gaming. Luxembourg.

Avtonomov, V. S. (2005). Improving economic education. Moscow. Logos, 10.

Babeshko, L. O., \& Labsker, L. G. (2001). Game methods in managing the economy and business. Moscow, 464.

Banko, N. A. (2002). Formation of professional pedagogical competence of future engineers (Unpublished master's thesis). Volgograd, 218.

Belyaeva, A. P. (1995). Perspective directions of development of vocational education in Russia St. Petersburg, 186.

Bibler, B. C. (1998). Culture as a dialogue of cultures. Problems of the Middle Ages, 1310, 15-45.

Borisova, N. V. (1991). Methods of choosing the forms and methods of active learning theoretical model. Moscow.

Bozovic, L. I. (1968). Personality and its formation in childhood. Moscow. Education, 464.

Bunkina, M. K., \& Semenov A. M. (2000). Economic man. Moscow, 176.

Burgonova, G. N., Gulpenko K., \& Kamordzhanova, N. (2000). Business games and the situation on accounting. Moscow: Finance and Statistics, 384.

Davydov, V. V. (1986). Problems of developmental education. Moscow.

Demicheva, N. V. (2009). Realization of pedagogical techniques in the preparation of accounting personnel in institutions of secondary vocational (Unpublished master's thesis). Moscow, 208.

Dubovitskaya, T. V. (2004). The development of self-actualizing personality of the teacher: a contextual approach (Doctoral dissertation). Moscow, 349

Esenkov, Y. V., \& Ashlapova, T. V. (2004). System control the quality of training. Vocational education, 6, 22-24.

Hessen, S. I. (1995). Outlook and education. Education and Pedagogy of the Russian foreign countries. Moscow, 105.

Leonov, A. N., \& Leontiev, A. N. (1982). Motives, emotions, personality text. Moscow: Nauka, 71-81.

Leontiev, D. A. (1999). Psychology meaning of the text. Moscow: Meaning, 487.

Marshall, A. A. (2007). The basics of economics (Bomkina, V. I). Moscow. Eksmo, 831.

Martynenko, O. O., \& Chernaya, I. P. (2007). Formation and evaluation of professional competencies of managers in the learning process text. Higher education in Russia, 9, 86-91.

Masalimova, A. R., \& Nigmatov, Z. G. (2015). Structural-Functional Model for Corporate Training of Specialists in Carrying Out Mentoring. Review of European Studies, 7(4), 39-48. http://dx.doi.org/10.5539/res.v7n4p39

Nikitina, N. N., Zheleznyakova, O. M., \& Petukhov, M. A. (2002). Based on professional and pedagogical activity. Moscow: Mastery, 281.

Novikov, A. M. (2000). Russian education in the new era. Moscow: Egves, 272.

Petrovskiy, A. B. (1981). By understanding the person in psychology. Questions of psychology, 2, 40-46.

Petty, A. A., Smith, D., Ricardo, A., Keynes, J., \& Friedman, M. (2000). Classical Economic Thought. Moscow: IzdEksmo-Press, 896.

Purin, V. D. (2006). Pedagogy of vocational education. Rostov, 249.

Rubinstein, S. L. (2004). Fundamentals of General Psychology. St. Petersburg, 678.

Scheler, M. (1999). Resentment in the structure of morality. St. Petesburg: "Nauka", "University Book".

Schumpeter, I. A. (2004). History of Economic Analysis (B.C. Avtonomova). St. Petersburg: The School of Economics, 678 .

Serikov, V. V., \& Bolotov, V. A. (2003). Competence model: from the idea to the educational program. Pedagogika, 5, 10, 11.

Shaidullina, A. R., Krylov, D. A., Sadovaya, V. V., Yunusova, G. R., Glebov, S. O., Masalimova, A. R., \& Korshunova, I. V. (2015). Model of Vocational School, High School and Manufacture Integration in the Regional System of Professional Education. Review of European Studies, 7(1), 63-67.

Shcherbakov, E. F., \& Esenkov, V. (2005).Organizational form of training in an educational institution of 
secondary vocational Ulyanovsk, 80 .

Snopko, N. M. (2008). Formation of socially open system of vocational education. Thesis. Moscow, 351.

Telegina, N. V., Galimova, E. G., \& Masalimova, A. R. (2015). The Structure and Content of the Model of Pedagogical Conditions Binary Approach to Optimization of Control and Diagnostic Functions in Teaching "General pedagogy" to Students. Asian Social Science, 11(1), 364-368.

Verbitsky, A. A., Arutyunov, Y. S., Borisov, I. V., \& Solovyova, A. A. (1988). Business game. The technique of constructing a business game. Moscow: Thought.

Vifliemsky, A. B. (2004). Russian state no longer guarantees the priority of education. Education, 8, 21-36.

Zhukova, N. V. (2006). Contexts personal culture in the learning process text. Higher education today, 8, 27-29.

Zinchenko, V. P. (1991). Worlds of consciousness and structure of consciousness. Questions of psychology, 2, 14-36.

\section{Copyrights}

Copyright for this article is retained by the author(s), with first publication rights granted to the journal.

This is an open-access article distributed under the terms and conditions of the Creative Commons Attribution license (http://creativecommons.org/licenses/by/3.0/). 